\title{
Through Knowledge to Power: How Modern Transformations of Society Create New Dimensions of Political Power
}

\author{
Oleg Lyakhovenko \\ Lomonosov Moscow State University, Moscow, Russia
}

\begin{abstract}
Since famous writings by Galbraith, Bell, and Toffler, we know that modern conditions of economic competition, technical progress, and growing speed of information flows raise the role of organized knowledge in social life. In the middle of 20th century, growing complexity of society and production processes gives birth to "The New Industrial State" as difficult system based on knowledge, specialization, and unique competences. Here rises the technostructure. In the very end of 20th century, most developed countries turn to post-industrial society. Society itself becomes more and more complex. Developing technologies of communication fasten all the social processes. Also, politics faces the third wave of democratization and vast expanding of non-governmental bodies, competing parties, and new political actors. As a result, political scientists, analysts, "think tanks", spin-doctors, political experts, and security advisers - all who can be called knowledge elite — become a significant part of both political and administrative power. To the extent they take part in policy making, influence on decision-making or are involved in everyday, routine work of political and administrative institutions, they could be supposed as technostructure of political sphere. However, knowledge elite is not — and probably will never be — a strong body which suppose itself to be an autonomous subject in politics or could dictate its will to decision-makers. Politics still remains a realm of political will, where elites possess power, electorate chooses politicians, parties compete between themselves. But even if classical idea of power still belongs to traditional actors and institutions, new dimensions of power emerge from knowledge elite.
\end{abstract}

Keywords: political power, knowledge elite, scientific elites, "think tanks"

Modern conditions of social, economic, and political development, growing complexity of all social and political processes and, actually, internal society's drift toward new era- "net era", the era of quickening information flows and network-organized interactions within and beyond society—update the classical issue of relations between knowledge and power.

Since Antique Greece and, taking into account the Great Asian East, since ancient civilizations of India, China, Mesopotamia, and Judea, we know that possession of knowledge - in fact-always meant the possession of power. Those who possessed knowledge could - to a greater or lesser extent - not only realize themselves in social life, but also influence on politics and economy. In this case, the philosophical, theoretical knowledge, inner personal vision meant not less than prominent technical qualification in mechanical arts, and sometimes - much more. That is why we speak about intellectual leadership in politics which on long historic

Corresponding author: Oleg Lyakhovenko, Candidate of Sciences, senior researcher, Department of Political Science, Lomonosov Moscow State University; research fields: scientific elites, political elites, and theory of politics. E-mail: oleg.lyakhovenko@gmail.com. 
scale quite often became philosophy (or the history of philosophy) and on much closer horizons - in very practical manner determined politics, economy, and international relations. Of course, Plato failed to implement his dream of the ideal state - but this fact seems rather to be an example of Utopia's lack of vitality and should not lead us away from the essence.

Furthermore, if we speak about social structure, since ancient times most powerful social groups tended to be also the most educated ones - of course, according to the criteria of the particular epoch. To belong to elite meant to possess great perspectives for accumulating knowledge. Even in Middle Ages, when only few earls pretended to embody the great intellectual leadership by their own personalities, we can see Holy Catholic Church and its abbeys - which were not only religious, cultural, and educational, but also political and economic centers. Globally, that situation changed only in the 20th century-when the revolt of the masses destroyed the traditional social hierarchy, paving the way to higher education, political power, or economic leadership for wider social groups and individuals.

Thus, the very issue of relations between knowledge and power is not something newly emerged. But it is rather obvious that something has fundamentally changed in recent decades, changed comparing not with Ancient Greece but even with the end of 19th and the beginning of 20th century. So where to search the answer?

Since famous writings by G. Galbraith, D. Bell, and A. Toffler, it is widely known that modern conditions of economic competition, technical progress, and growing speed of information flows raise the role of organized knowledge in economic sphere. Today personal qualification, inner knowledge (which could be both theoretically organized and easily translated, but also deeply individual and complicatedly specified), individual ability to adopt, study, and change him- or herself become the basic precondition for economic development and successive competition. Knowledge itself becomes an exceptional factor for high-tech production and difficult industries - both traditional and "post-industrial". But at the same time, and in the same exceptional extent - rises the role of knowledge as leading and organizing force for all economic processes.

"Know-how" in fact means not only direct access to unique technologies [bio-tech, IT (information technology), composite materials, space programs, electronics, nanotech, etc.], but also exact knowledge what to produce, where to invest, and when to buy in. The last point-when-now seems to be more and more important, and its meaning tends to grow up in the reality where information and capital flows permanently accelerate its course and the cost of failure in global market competition goes up in incomparable scale.

In this paper, the author is going to introduce a specific theoretical vision on the very similar processes which are on in political sphere. Global accelerating of all processes within society, rapidly upspringing social networks (both in IT and sociological senses), general increase of complexity in social organization all together complicate political sphere and thus enhance the role of organized knowledge in politics.

The author's analysis includes three main aspects of these transformations, so the main part of the paper consists of three chapters.

In the first chapter, the author analyzes the basic shift in social organization and economic production processes which paved the way for Galbraith's technostructure and-in politics-allowed to speak about special kind of technostructure of the political sphere.

In the second chapter, he tries to explore the deeper foundations for modern social and political transformations. The emphasis falls on more profound changes in the very nature of social power which mean that nowadays within traditional forms of power (such as political will and administrative governance), new 
dimensions of power rise - and the expert and consultative power is the first one. The role of expertise and political advising grows on all scales from the very top of political structure to its middle and lower levels. This tendency tends to grow up since nowadays, strong, inflexible, stable technostructure of the middle of 20th century tends to be transformed and re-organized in primarily network ("net- ") forms - dynamic, flexible and, thus, unstable.

In the third chapter, he recurs to the main concepts of scientific and knowledge elite and comes to general conclusions. Also, he shows how administrative advisers who work within bureaucracy and "external" structures and personalities (experts, "think tanks", scientific elites, etc.) being linked together into a knowledge elite network, become a significant part of technostructure of political sphere. Unfortunately, although all these trends do rise up and expert power influences more and more on political processes, knowledge elite is not yet —and probably will never be - a strong body which supposes itself to be an autonomous subject in politics or could dictate its will to decision-makers. In that sense, politics still remains a realm of political will, where elites possess power, electorate chooses politicians, parties compete between themselves, non-governmental bodies draw together the social, civil, and political agenda, and so on. But even if classical idea of power still belongs to traditional actors and institutions, new dimensions of power do emerge from knowledge elite.

\section{The Rise of Knowledge Elite}

Institutional economic studies of 1950s-1960s (and the leading hand, undoubtedly, belongs to G. Galbraith) revealed how and in which forms technical and technological development and growing accumulation of knowledge used in industrial production give birth to a special form of industrial system- "The New Industrial State". This system is used to be described in terms of high concentration of capital, powerful integration within and sometimes between different industries, growing ability of major firms to influence not only on certain market segments, but on the very structure and development of the whole markets, and so on. In here, Galbraith coins the new term "corporation" which is a rapidly developing, possessing huge capital, and complexly organized structure which uses and produces technics and technology as its basic tools. Thanks to specialization and separation of functions, corporation becomes more and more complex and diversified. Since technics and technologies go forward, the role of specialization also rises. Thus, corporation's staff is becoming not only more and more uninterchangeable, but for some times - turns out to be unique in its competence, abilities, and skills. This is what Galbraith called "the six consequences of modern technics' implementation": growing scopes of all processes and businesses which now include many inner steps and "micro"-aims; complicated infrastructure used by aim-oriented professional groups; specialization of staff; growing role of personnel management; rising of planning (of course, not in Marx's meaning). As a result, rises the inflation of knowledge: Management and staff should learn new again and again during their professional life.

Another consequence is closely connected with the growing separation between management and shareholders - and, in fact, between functions of management and functions of shareholders. But besides that, some more profound transformations take place. Because of growing complexity of production processes, separation of competence, and complication of organizational structure within corporation transaction costs also rise, and above all-transaction costs in circulation of information. That is why becomes impossible to concentrate all the functions of management, planning, decision-making, and implementation in the single headquarter, and within headquarter - in the single highest management body. In reality, many and many credentials, competences, and managerial functions descend down the middle and lower levels of corporate and 
administrative hierarchy. But in fact, besides documents circulation and delegated authority, real managerial functions go "down" the corporate hierarchy, too. And this does not mean mechanical powershift. More precisely, we should speak about arising of new forms of management, complex, nonlinear, in which all the levels of corporate hierarchy are involved in decision-making and implementation process control, even (too little, but not less real extent) the lowest. That is what Galbraith called technostructure.

Of course, all these facts do not abandon the role of leadership, management, and so on, which still remains the hard core of any organized process. But they show that in this new situation-complex and dependent from many factors, relations, information flows, and reconciliation processes - new quality of power emerges. Even if there is only one person which makes decision, the decision-making process depends on many, and in here, the role of organized knowledge and specific precise competence does matter.

Now we should specify that Galbraith, of course, described the transformations within the system of economic production, in which the role of people who possess technical skills, experience, and abilities rose in uncomparable with any past epoch extent. But now we can see that almost all the processes he describes seem to be appropriate also for political sphere. That does not mean only the fact that administrative and bureaucratic hierarchies also transform in very similar direction (although, they do - anyway, did in the second part of the 20th century). The structures deeply involved in decision-making, even those who stand beyond administrative bureaucracy, also face the same shift toward growing interconnection and interdependence of all the parts within governing objects. As Galbraith wrote, decision-making needs information, so certain power passes on those who possess necessary information. So the fountainhead of power shifts once again-toward organized knowledge.

In more precise and categorical manner, these transformations were formulated by A. Toffler who claimed that there was no one great philosopher or intellectual of the past could not even imagine the extent of powershift. Due to this powershift, or metamorphosis of power, both power and wealth now depend on knowledge and, otherwise, knowledge lost its appendant position toward power and wealth and became their essence.

To the extent in which the speed of transformations grows, traditional management (both political or administrative and economic) also faces the lack of adequacy toward new challenges. Information flows accelerate so fast and their frame changes so fast that no one single highest management body is able to handle all the processes on his own. Huge bureaucratic structures organized as big vertical structures show less and less adaptability to changing external conditions. And on the other hand, to the extent in which corporate organizations still remain huge and complex bodies (what, for some time, allows them being too big to fail), they aspire to re-establish themselves, their organization and-above all-their management toward more flexible, projective, aim-oriented structures. And this trend suits both economic and political sphere.

Also, we should point out some specific tendencies which also became actual for political sphere. Since the very beginning of the 20th century, societies face the revolt of the masses. All the social processes become mass. Erosion of traditional structures, atomization of individuals, growing complexity of social institutions, arising flexible movements and non-governmental bodies, democratic movement and "waves of democratization" irreversibly transformed politics. Political leaders, parties, and governmental bodies face the necessity to rule - or at least to interact with—“organized complexity", big social, non-governmental, and economic systems with many interconnected variables. And in here, no one political body could assume all the political management. That is why decentralization processes spring up and new functions in exercising power 
descend down the political hierarchy. And this might be seen at both formal and informal levels. At formal levels, we see the growing regionalization, subsidiarity, local government, and new opportunities for civil participation, at informal — growing responsibility of middle and lower bureaucratic levels.

So the real political power to make and implement decisions go down from the highest point of political hierarchy to the middle and lower levels or sometimes shifts (is delegated) to special horizon-organized projective certain-aim-oriented structures. And here arises the subject which is to be called technostructure of the political sphere.

That is why grows the role of those elements of political sphere which are responsible for independent and autonomous decision-making at the local level. Micro-politics and micro-leadership are also going in importance. And, eventually, demand for competent and efficient maintenance for political decision-making at all the levels (from local to global) is also rising. Of course, that does not mean that traditional political subjects lose their power - they do not lose. That means that role of consultative and analytical structures - and, in fact, their power or, at least, ability to influence on political decision-making-rises. Significant peculiarity is that we are not talking about any kind of judicial power or specially accepted laws, and at the same time, we are not speaking about insider job. Our emphasis falls on the fact that abilities (and possibilities) to influence on political process based on possessing knowledge, professionalism, qualification, extraordinary technical and technological skills take on new and qualitative significance. The role of ability to work with information and to model and forecast processes rises. And all these new dimensions of power are closely connected with the function of knowledge, competence, and possession of information - in fact, with organized knowledge.

As a result, rises the role of knowledge elite - closely connected with both academic studies and also practical politics and economy and realizing its function of knowledge in politics and, broader, in the relations about social power at local, governmental, and global levels.

\section{Network Principle, Elite Shift, and New Dimensions of Political Power}

Giving his wide observation of "The New Industrial State" and deep transformations within society and economic production system, G. Galbraith observed (following J. Burnham and his "managerial revolution") the real tendency on separation between management and shareholders. But at more fundamental and profound level, he also demonstrated the deep processes of "the diffusion of power". He showed how (in economy) decision-generating, decision-making, and executive centers shifts down the power vertical and gives birth to some new forms of power - consultative and analytic. He also showed that industrial system itself- despite the fact that many corporations establish their own educational and research and development centers-has a fundamental lack of specified knowledge and technologies. This fact made the system to search for them outside its borders - in universities and educational centers. Possessing capital does not give guarantees that necessary knowledge and technologies also might be found, received, and applied.

Nowadays, we should note that almost all these trends and tendencies (formulated, once again, for economy and corporate sector) are also appropriate for political sphere. Political system is becoming more and more complicated in its regulation and administrative functions. Besides that, informational flows also fasten, new agendas change each over with higher and higher speed, and the state also faces the necessity to deal with many social, economic, ecological, and cultural challenges. That is why new forms of political power organization, political communication, and political governance formulate profound request for growing participation of knowledge elite in political and economic processes. 
In the introduction of this paper, we already noted that neither consultative power nor analytic one seem to be something absolutely new in politics. It is true that political advisers existed during all the mankind history and in all societies. Also, at all times, there existed a clear comprehension that rude force often yields to indirect actions based on ruses and more profound access to information. It is simplest to remember $\mathrm{N}$. Machiavelli and his "lions and foxes", or Sun Tzu, or other thinkers and strategists. Nonetheless, some principle changes in the usage and palliation of knowledge do take place. D. Bell expressed the essential core of this transformation. He showed that real and most significant change lies in the nature of knowledge and is closely connected with codification and wide spread of theoretical knowledge - which takes part in production of goods, services, and new knowledge. This knowledge-scientific knowledge, technical and humanitarian - is produced, translated, and used on the systematic basis. And since science develops to its mature state, the role of theoretical knowledge — and knowledge elite as specific social group —also rises.

More interesting thing is that transformations within technical progress, based on intellectual technology and theoretical knowledge instead of mechanical technics, determine significant changes in social structure organization. Here we come to the concept of post-industrial society.

As D. Bell, A. Toffler, and their followers showed, on the first, most easily viewed and described level, post-industrial society might be characterized in terms of formal proliferation of service sector in economy and growing role of informatization. These statements seem to be obvious and commonly accepted. But at more fundamental level, this new-maybe, only upspringing — form of social organization is characterized with growing role of knowledge in surplus production, all social processes and information flows acceleration, and radical complexification of society itself. As a result, economy becomes complex and dynamic structure permeated with rapidly changing their intensity and direction flows - and, finally, breaks away from "real sector", generating above all traditional material structures complicated and very dynamic virtual superstructure.

Most important results of these changes are the colossal growth of speculative capital, massive expansion of turbulence and uncertainty as constantly present factors - and permanently growing probability for system risks to trigger with inevitable increase of consequences scale.

Power, dominance, and leadership now tend to be implemented not through big corporate, administrative, or governmental structures, but through priority access to information and communication centers. And now companies and actors could be successful not due to capitalization, access to markets, lobbying (although significance of them still remains), but primarily to the extent in which they can manage information flows, form the political and economic agenda and thus influence on capital flows, diversify or concentrate industries and radically transform their production processes according to new demands of market.

All these aspects have meaningful significance for comprehending new dimensions of politics - and new challenges for political sphere, too. In most concise and succinct form, the meaning of this problem was conveyed by D. Bell when he asked whether old institutions and organization structures would be able to cope with this extraordinary diversity of interconnections, interactions, and interrelations. And he was right because the nowadays, existing administrative and political hierarchies as more conservative and less flexible structures often fail to run after changing economy and informational agenda. Political administration, still possessing formal levels of influence, especially in tax, monetary, and budget policy or in licensing, lose many of its real levels to determine the direction and substance of economic development. In its own part, economy also seeks new forms of influence on politics and interaction with the state, and sometimes it goes in vanguard of deep 
social changes. As a result, the very substrate of political power not only descents down the technostructure of political sphere, but also shifts to contiguous fields-economy, corporate sector, intellectual centers, and cultural communities.

Another substation feature of post-industrial society transformations derives from the concept of network, and primarily social network (in sociological sense) as specific form of social organization. This form can be described in terms of non-linearity, incompleteness, numerous horizontal ties between actors and participants. Network neither has singular "genetic code", or single shaping principle, nor focal point which determines interaction within network. Among the main characteristics of network as organizational form, dynamic principle should be mentioned. And it would be really difficult to explain network in traditional categories of static place, point, space, time, and hierarchy. Much more important thing is the speeds of flows within network. And that is why post-industrial society can also be considered as network society, with network as key organizational principle according to which all traditional hierarchies and institutions are to transform.

In fact, knowledge elite seems to embody this network principle as its dominant peculiarity.

\section{Knowledge Elite in Political Dimension}

As it was mentioned above, knowledge elite stands very close to the very fountainhead of modern social, economic, and political changes. Being deeply involved in producing information, developing technologies and consultation on major directions of business expansion and political processes administration, knowledge elite often appears as productive elite. From another side, it is closely linked with scientific elite and R\&D (research and development) centers. That is why it will be important for the analysis to clarify how in fact knowledge elite is organized in sociological sense, in what social institution is localized and what form of social organization shapes at the present stage.

In most narrow meaning of this term, we can single out scientific elite as special group most deeply involved in production of theoretical knowledge. Institutionally, scientific elite is localized in academic structures (universities, research centers), corporation R\&D centers, and applied centers and structures among which we could mark "think tanks", "brain trusts", analytical centers, and so on. Remarkable thing is that this third aspect is mostly linked with humanitarian sphere and mostly oriented on social, political, cultural, and economic studies, industry research, and security studies. Political sphere and governmental bodies seem to primarily deal with this organizations and institutions.

In broader meaning, knowledge elite can be understood as intellectual and productive elite. These groups might but also might not be connected with the academic sphere, especially when we speak about public intellectuals or best-qualified engineers and industrial and IT specialists who work in application fields. But these groups with no doubt are deeply involved in processes of material and creative production based on qualifications, possession of knowledge, and unique or uninterchangeable competence.

The third and the broadest view on knowledge elite let us take into account wide set of social groups and single individuals connected between themselves and organized according to network principle, deeply involved in intellectual creativity and participating in significant social meanings generation and intellectual-based surplus value production. This viewpoint should not be mixed up with Richard Florida's creative class - primarily due to the fact that, from one side, knowledge elite is a broader category than creative class and, from the other side, creative class itself has its own separate segments (for example, liberal arts people) which are much less connected with theoretical knowledge. However, these two terms seem to have 
many points of intersection.

So if we try to find a special model which brings together three views observed above, we should specify most significant characteristics of knowledge elite which seem to be appropriate for all these visions. These are:

(1) Intellectual activity and participation in intellectual production (technical or humanitarian);

(2) Possessing the unique or profound knowledge and competences;

(3) General creativity as key principle of intellectual production;

(4) Decentralized organization even in vertically-integrated hierarchies.

Deepening and displaying the last statement, we should mark that knowledge elite is not a single, strong organized, and formally institutionalized social class or body or hierarchical structure. Knowledge elite tends to be a kind of decentralized, in very specific way organized network, or rhizome, which links specific actors who possess knowledge and information but belong to different formal hierarchies and structures. And since traditional concept of power still belongs to the state, politicians, and political leaders, knowledge elite becomes the link which permeates different structures, corporate or political, and let them react on external challenges and threats in adequate, efficient, and effective way. In this network, or rhizome, singular individuals, projective groups, and whole institutions are linked with various and numerous ties - professional, educational, private, and others.

In politics, the knowledge elite is closely connected with technostructure of political sphere and to some extent forms it. At the same time, technostructure itself tends to be re-organized in network- "net"-forms, trying to become more flexible and open to new impulses from the environment.

From more intent sociological approach, in politics, this knowledge elite network includes numerous scientific communities, professional associations, academic institutions, analytical and consultative structures, "think tanks", "brain trusts", their singular representatives, political advisers and experts, "spin-doctors", political and administrative bodies' expert and analytical staff, and other participants involved in the same field. All these people and groups according to their competence and professional skills, influence on strategic decision-making process, and take some part in implementation of political will and maintenance of everyday, routine politics.

At the same time, it would be wrong to insist on the idea that knowledge elite, this "intellectual class", becomes a political class, substitute traditional political actors or concentrate formal power. Quite clear that in electoral campaigns, intellectuals and those people who used to lead nonpublic life are often beaten, even if they are good specialists in political decision-making or deeply immersed in political science. In practice, neither technostructure (in hierarchical or network form) nor scientific and knowledge elites become independent political actors. Moreover, knowledge elite, in fact, is not a strong and formally institutionalized body which supposes itself to be an autonomous political actor. To a great extent, it still stays no more than a network (and even various networks) of individuals and individuals' communication — even if some of them are powerful enough to influence on certain administrative body and politician or to promote a special economic, social, and informational agenda.

In that sense, politics still remains a realm of political will, where elites possess power, electorate chooses politicians, parties compete between themselves, and so on. Power itself is becoming more and more dependent on access to knowledge, but those who possess knowledge are still put into circumstances where they follow the rules established by power-holders. At least, there is democracy, and political and electoral campaigns seem to be more democratic than knowledge meritocracy. But social demand and also more profound inner request 
of political system for knowledge application are rising, too, and due to this fact, analytical and consultative power tend to extend its field.

All these tendencies and trends form a really complex and knotty impact. Quite obvious that contradictions nascent here will become more and more apparent in the 21 st century throwing down new challenges for society and political science to face with.

\section{References}

Bell, D. (1973). The coming of post-industrial society: A venture of social forecasting. New York: Basic Books.

Bell, D. (1976). The cultural contradictions of capitalism. New York: Basic Books.

Burnham, J. (1941). The managerial revolution: What is happening in the world. New York: John Day Co.

Castells, M. (1996). The rise of the network society. Oxford: Blackwell.

Florida, R. (2002). The rise of the creative class: And how it's transforming work, leisure, community, and everyday life. New York: Basic Books.

Galbraith, G. K. (1958). The affluent society. Boston: Houghton Mifflin Company.

Galbraith, G. K. (1967). The new industrial state. New York: Houghton, Mifflin.

Granovetter, M. (1983). The strength of weak ties: A network theory revisited. Sociological Theory, 1, 201-233.

Grant, R. M. (1996). Toward a knowledge-based theory of the firm. Strategic Management Journal, 17, 109-122.

Latour, B. (1997). On actor-network theory: A few clarifications. Retrieved from http://faculty.georgetown.edu/irvinem/theory/ Latour-clarifications.pdf

Touraine, A. (1971). The post-industrial society. Tomorrow's social history: Classes, conflicts and culture in the programmed society. New York: Random House. 